\title{
Storm-induced coastal hazard assessment at regional scale: application to Catalonia (NW Mediterranean)
}

\author{
E. Bosom ${ }^{1,2}$ and J. A. Jiménez ${ }^{1,2}$ \\ ${ }^{1}$ Laboratori d'Enginyeria Marítima, ETSECCPB, Universitat Politècnica de Catalunya, Barcelona, Spain \\ ${ }^{2}$ International Centre for Coastal Resources Research, Barcelona, Spain \\ Received: 23 March 2010 - Revised: 8 June 2010 - Accepted: 20 June 2010 - Published: 2 August 2010
}

\begin{abstract}
A methodology for coastal hazard assessment at regional scale is presented and applied to the Catalan coast (NW Mediterranean). The method separately evaluates erosion and inundation hazards by using wave time series and beach characteristics (slope and sediment grain size). Obtained hazard time series are fitted to extreme probability distributions for different coastal sectors which are defined in function of local wave climate. This approach allows to compare the spatial variation of hazard intensities for a given probability of occurrence and, thus, to objectively identify the most hazardous areas along the coast in terms of erosion and inundation. Obtained results indicate that the coast north of Barcelona is more hazardous than the southern coast regarding inundation for any given probability. With respect to storm-induced erosion, the central coast of Catalonia is the less hazardous area, although spatial variations in erosion along the coast are smaller than the observed for inundation.
\end{abstract}

\section{Introduction}

Coastal vulnerability to storms can be simply defined as the potential of a coastal stretch to be harmed by the impact of a storm. Its assessment includes the modification of the coastal geomorphology (morphodynamic response to storms, i.e. coastal hazards) and the affectation of socio-economic and environmental values. This will serve managers to assess the expected magnitude of damages along the coast, to make (informed) decisions on mitigation/adaptation strategies and to allocate the required resources (frequently limited) to those locations more prone to be affected. Thus, the
Protocol on ICZM in the Mediterranean (PAP/RAC 2007) advises countries to undertake hazard assessments of coastal zones to address the effects of natural disasters.

During the impact of a storm on the coastal zone, different processes take place with different morphological consequences and induced damages (e.g. Morton and Sallenger, 2003). Due to this, for practical purposes it should be desirable to individually assess the magnitude of each of the induced hazards. The two main induced coastal hazards are erosion and inundation and, although they frequently verify simultaneously, there are storm conditions where beach erosion dominates whereas inundation is the most relevant hazard under other situations. If information on the magnitude of each hazard is available, the manager should know in advance the expected type of damages and would be able to select the best measures to mitigate them. Finally, the quantification of the relative contribution of each factor driving a given hazard should also be relevant, in order to address the problem more efficiently. This is taken into account in this work by considering the storm-induced hazards to be the result of two main contributors: (i) storm properties and (ii) the coastal geomorphology.

Within this context, the main objective of this work is to develop a methodology to assess storm induced coastal hazards at regional scale by taking into account (i) the different induced hazards, (ii) the different contributors to the hazard's intensity and (iii) permitting to compare the intensity of the hazard along the coast associated with a given probability level. This methodology has been developed for and applied to the Catalan coast but can be easily adapted to other coastal zones.

\section{Correspondence to: E. Bosom}

(eva.bosom@upc.edu)

Published by Copernicus Publications on behalf of the European Geosciences Union. 


\section{Study area and data}

The Catalan coast is located in the NW Mediterranean (Fig. 1). It has a length of approximately $600 \mathrm{~km}$ and it is formed by a large variety of coastal types, such as cliffs, embayed beaches, long sandy beaches and deltas.

Storm properties along the Catalan coast have been characterized by using the best available information, which consisted in: (i) recorded data from 5 wave buoys that have been operating along the coast from the $80 \mathrm{~s}$, and (ii) hindcast wave data for the period 1958-2001 obtained in the framework of the Hipocas project (Guedes-Soares et al., 2002). Both data sources were used to build up 50-year long (1958-2008) time series in 5 areas along the Catalan coast. Each time series was built after calibrating hindcasted data by using the period of simultaneous buoy recording. Resulting time series were composed by the values of the annual maximum storm which was characterised by the significant wave height, $H_{s}$, peak period, $T_{p}$ and direction, $\theta$, at the peak of the storm (when the maximum $H_{S}$ verifies) and the storm duration (defined as the period during which $H_{s} \geq 2 \mathrm{~m}$, Mendoza and Jiménez, 2008).

Beaches were characterized by main variables affecting the intensity of the hazards such as beachface slope and sediment size. Data gathered in about 300 beaches were analyzed to classify them in six beach types by using beachface slope and sediment grain size as classification variables.

\section{Storm-induced coastal hazards}

\subsection{Generalities}

As mentioned before, the considered storm-induced coastal hazards are erosion and inundation. These processes can significantly vary in terms of type of response and intensity at small spatial scales (see e.g. Morton and Sallenger, 2003). Since the methodology has been developed to be applied at regional scale, profile erosion and inundation are assumed to be homogeneous at the beach scale and, in consequence, they are evaluated as a single value per beach. Local variations should be considered when the regional hazard assessment needs to be downscaled at the beach level.

Although both processes are induced by the same storm event, they are separately assessed in this work to properly identify the dominant hazard during a given storm and location. In the developed framework, both hazards are parameterized in function of storm (wave) properties and beach characteristics by using two simple predictors.

Beach erosion is represented by the potential volume of sediment eroded from the beach, $\Delta V$, during the impact of the storm. This volume is calculated by using the predictor proposed by Mendoza and Jiménez (2006, 2009)

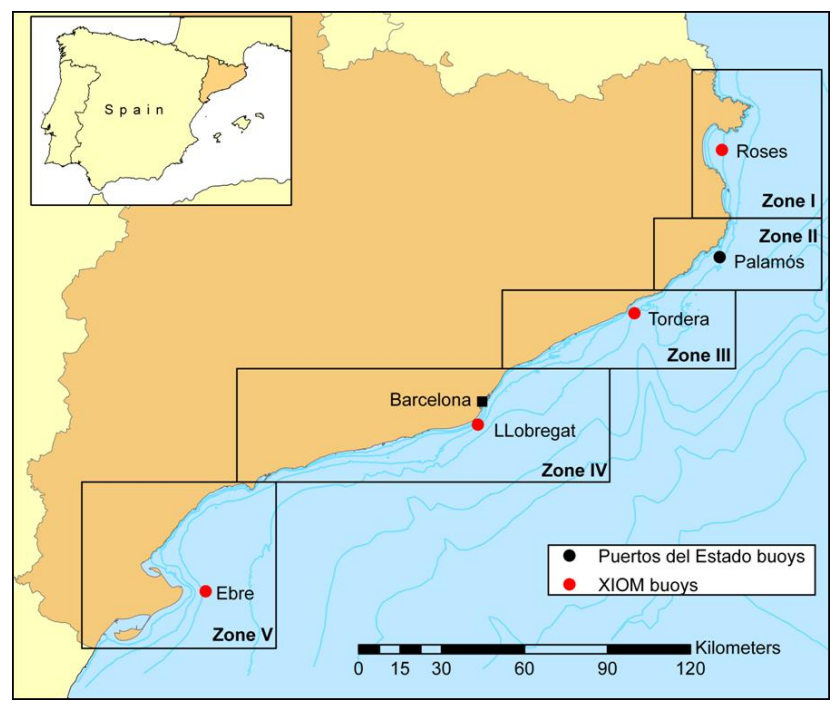

Fig. 1. The Catalan coast, study area and location of wave sectors.

$$
\begin{aligned}
\Delta V & =2.9(J A \tau)+6.73 \\
& =\left[2.9\left(\left|D-D_{\text {eq }}\right|^{0.5} \tan \beta\right) \tau\right]+6.73
\end{aligned}
$$

where $J A$ is a parameter predicting beach profile changes (Jiménez et al., 1993), $\tau$ is the storm duration, $D\left(=H_{s} / \omega_{f} T\right)$ is the dimensionless fall velocity parameter (Dean, 1973), $D_{\text {eq }}$ is its value at equilibrium, $\tan \beta$ is the beach slope, $\omega_{f}$ is the sediment fall velocity and $T$ is the wave period.

The meteo-oceanographic characteristics of the Catalan coast determine that the wave-induced contribution to water levels during storm dominates over the storm surge one (Mendoza and Jiménez, 2008). Due to this, the potential inundation during storms has been parameterized by the waveinduced run-up. In this work, we use the run-up formula proposed by Stockdon et al. (2006), which is given by

$$
\begin{aligned}
& R u_{2 \%} \\
& =1.1\left(0.35 \tan \beta\left(H_{s} L_{0}\right)^{1 / 2}+\frac{\left(H_{s} L_{0}\left(0.563 \tan \beta^{2}+0.004\right)^{1 / 2}\right)}{2}\right)
\end{aligned}
$$

where $H_{s}$ is the deep-water significant wave height and $L_{o}$ is the deep-water wave length calculated for the wave peak period. To estimate the most hazardous conditions, run-up is evaluated at the peak of the storm.

\subsection{Hazard assessment framework}

The above presented predictors were implemented in a hazard assessment framework to be applied at regional scale. As mentioned before, the adopted approach is based on the use of extreme probability distributions of induced hazards. Thus, instead of comparing the effects induced by the impact 
of a given event along the coast, we compare the hazard intensity associated with a given probability. This framework is composed by the following elements and/or steps:

1. Selection of homogeneous sectors along the coast in terms of wave climate to define storm forcing conditions. For the Catalan coast five wave sectors have been selected.

2. Selection of beach types in terms of beach properties (sediment grain size and beach slope) to define receptor's (beaches) contribution to hazards along the coast. For the Catalan coast six beach classes have been defined. In this work we have used two main beach types: (i) dissipative, which are composed by fine to medium sands $(0.1 \mathrm{~mm}-0.4 \mathrm{~mm})$ and relatively mild slope beachface $(<1 / 10)$ and (ii) reflective, with coarse sands $(0.7 \mathrm{~mm}-1.0 \mathrm{~mm})$ and steep beachface $(1 / 6.5)$.

3. Built up of a storm time series for each wave sector from wave data. In this work, the storm time series has been obtained by using the annual maximum storm. This results in time series composed by 50 data (one per year) covering the period from 1958 to 2008.

4. For each wave sector and for each beach-type, hazard time series are built using the corresponding indicator. This is separately done for erosion and inundation using storm time series defined in step 3 and the corresponding beach characteristics (obtained in step 2).

5. Fitting hazard time series to extreme distributions (for each wave sector and beach characteristics sub-sector).

This methodology follows the response-approach to estimate the hazard extreme distribution, which has been recommended in different storm-induced risk analyses (e.g. Divoky and McDougal, 2006; Jiménez et al., 2009). The final result is a collection of hazard intensities associated with given return periods along the coast. Thus, to analyze the spatial variability in hazard intensity we select the target return period (probability of occurrence of the hazard) and then, compare the corresponding intensity for all the (wave) sectors and (beach characteristics) subsectors. As a consequence, obtained values along the coast do not necessarily correspond to the same event but to the equal probability response.

\subsection{Application to the Catalan coast}

Figure 2 shows the extreme distribution of storm-induced potential erosion along the Catalan coast for the two selected beach types, i.e. dissipative and reflective. Results are presented for each wave zone being I the northernmost zone (Roses) and V the southernmost one (Ebro).

When the erosion hazard intensity is analyzed by considering the beach type, fine-medium sand beaches are more hazardous than coarser sand ones at any given probability.

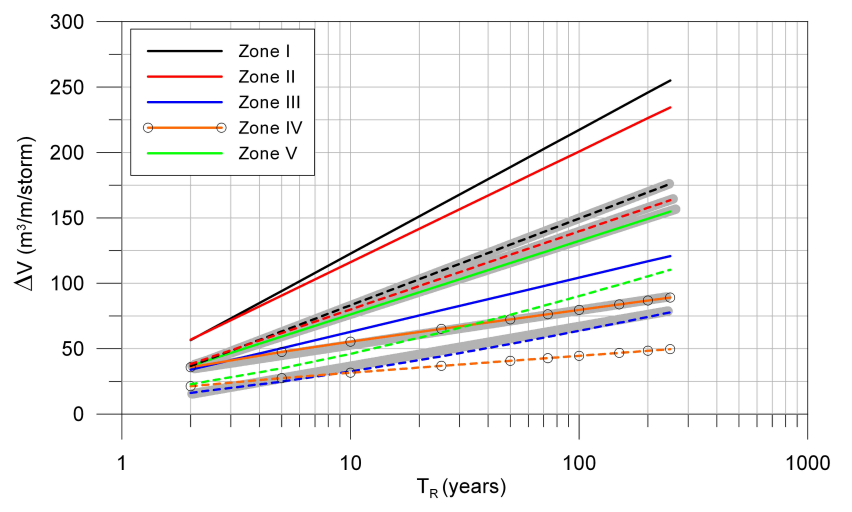

Fig. 2. Extreme distribution of storm-induced erosion hazard along the Catalan coast (solid line: dissipative beaches, dashed line: reflective beaches, shadow lines correspond to the most frequent beach type per wave sector).

If the contribution of local wave characteristics is accounted for, the N (zones I and II) and S (zone V) parts of the Catalan coast are the most hazardous areas whereas the central coast (Barcelona, zone IV) is the least one. For dissipative beaches, the magnitude of erosion increases up to $2-2.5$ times at the North (zones I and II) and 1.2-1.5 times at zones III and V, with respect to the estimated one for the central coast. This ratio increases for increasing return periods (Fig. 3). The same variation pattern is also observed for reflective beaches, although the increase in magnitude at the $\mathrm{N}$ with respect to the central coast is slightly larger than the observed for dissipative ones.

Figure 4 shows the extreme distributions of the inundation hazard along the Catalan coast for dissipative and reflective beaches. As it can be seen, the dependence on beach type is opposite to the observed for erosion, i.e. coarse sand beaches are more hazardous than fine sand ones at any probability. This is because beachface slope increases for coarser sands and, the run-up magnitude increases with beach slope. Considering the dominant beach type per sector, the spatial distribution of the inundation hazard shows two areas, northwards and southwards of Barcelona, with the $\mathrm{N}$ part being the most hazardous zone.

Figure 5 compares the magnitude of the inundation hazard associated with any given probability with respect to the ones at the central coast. In this case, the difference in magnitude does not present a significant variation with $T_{R}$ and, it is significantly smaller than the observed for erosion. The maximum increase in inundation hazard is about $45 \%$ for the $\mathrm{N}$ coast (sector I) whereas for the rest of the Catalan coast the increase in magnitude is smaller than $20 \%$ of the observed at the central part. 


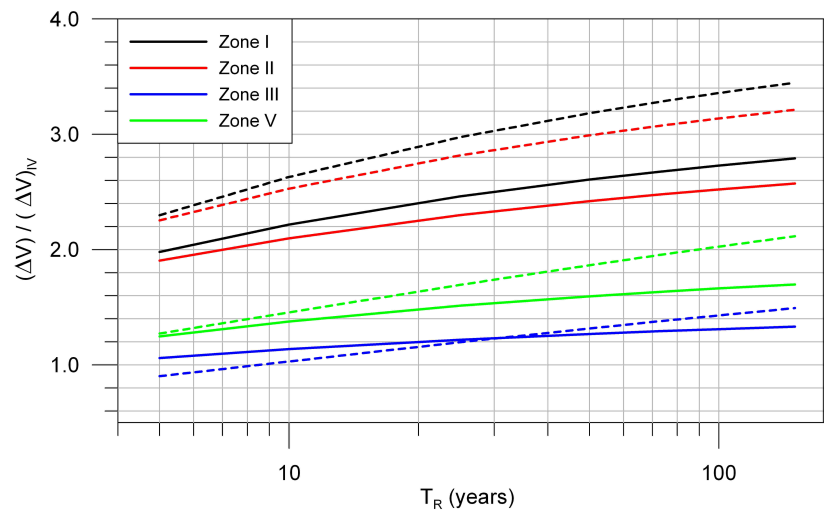

Fig. 3. Ratio of the magnitude of storm-induced erosion hazard for each wave sector with respect to the magnitude at the central part (Barcelona) of the Catalan coast (solid line: dissipative beaches, dashed line: reflective beaches).

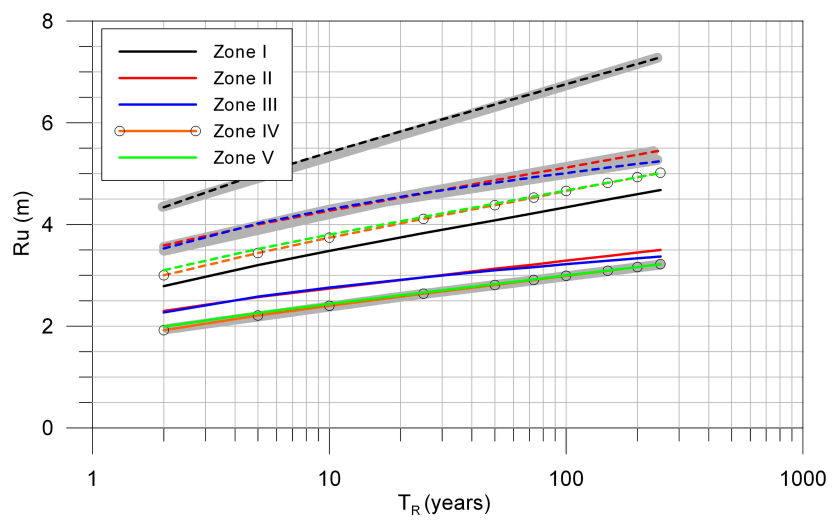

Fig. 4. Extreme distribution of storm-induced inundation hazard along the Catalan coast (solid line: dissipative beaches, dashed line: reflective beaches, shadow lines correspond to the most frequent beach type per wave sector).

\section{Discussion and conclusions}

In this paper, a methodology for storm-induced beach hazard assessment at regional scale has been presented. The method separately evaluates main induced hazards (erosion and inundation) in probabilistic terms. Results are presented as extreme distributions of hazards for different areas along the coast (depending on the wave climate) and, for different beach types (depending on the existing geomorphology). With these distributions, we can identify the most hazardous areas along the coast by comparing the intensity of a given hazard (erosion and/or inundation) associated with a given probability.

The methodology has been applied to assess storminduced hazards for existing beach types along the Catalan coast. The real distribution of hazards will depend on the spatial distribution of existing beach types along the coast,

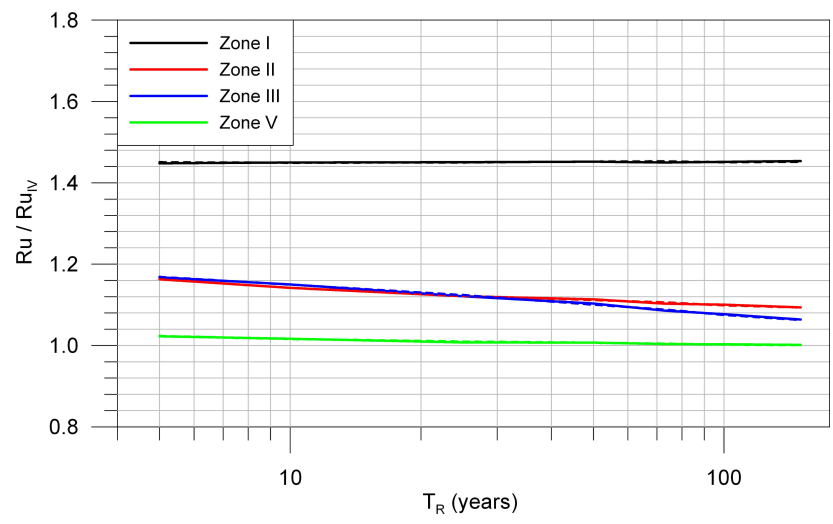

Fig. 5. Ratio of the magnitude of storm-induced inundation hazard for each wave sector with respect to the magnitude at the central part (Barcelona) of the Catalan coast (solid line: dissipative beaches, dashed line: reflective beaches).

i.e. reflective beaches dominate northwards of Barcelona and dissipative ones do at the southern coast. With this spatial pattern, real differences in the magnitude of erosion along the Catalan coast will be lower than the theoretical one which is obtained for all beach types (see shadowed lines in Fig. 2). On the other hand, this spatial distribution of beaches affects the inundation hazard in opposite manner. Thus, the difference in real hazard intensities at the $\mathrm{N}$ and $\mathrm{S}$ parts of the coast will be larger than the obtained per beach type (see shadowed lines in Fig. 4).

It has to be stressed that the obtained hazard values do not necessarily correspond to equivalent vulnerability ones, because they only account for the intensity of induced processes without including the capacity of the coastal system to cope with the hazards. To do this, we must include some beach variables characterising its capacity of response. Thus, when assessing vulnerability to erosion, the hazard intensity needs to be integrated with beach width and, in the case of inundation, the beach/dune height should be included.

By using this methodology, coastal managers could identify the most potential hazardous zones in terms of beach erosion and inundation along the coast for a given probability. If combined with actual beach characteristics (to convert hazards to vulnerabilities) this could be used to properly allocate resources to prevent/mitigate expected storm-induced damages along the coast. However, before applying this methodology in real situations, it is necessary to identify thresholds for the selected hazard indicators (erosion and inundation) that if exceeded could be used as proxies of the existence of coastal damages. A first validation has been done at regional level for Catalonia by Jiménez et al. (2010). 
Acknowledgements. This work has been done within the VuCoMa research project which was funded by the Spanish Ministry of Research and Innovation (CTM2008-05597/MAR). The first author was supported by a Ph D grant from the Ministry of Education of the Government of Spain. The authors thank the Department of Territorial Policy and Public Works of the Generalitat de Catalunya and Puertos del Estado of the Spanish Ministry of Public Works for supplying the data used in this study.

Edited by: J. Salat

Reviewed by: one anonymous referee

\section{References}

Dean, R.: Heuristic models of sand transport in the surf zone. Proc. 1st Australian Conf. on Coastal Engineering, Sydney, Australia, May 14-17, 208-214, 1973.

Divoky, D. and McDougal, W. G.: Response-based coastal flood analysis, Proc. 30th Int. Conf. on Coastal Engineering, ASCE, San Diego, California, September 3-8, 5291-5301, 2006.

Guedes-Soares, C., Weisse, R., Carretero, J. C., and Alvarez, E.: A 40years hindcast of wind, sea level and waves in European waters, Proc. 21st Int. Conf. on Offshore Mechanics and Arctic Engineering, ASME, Oslo, Norway, June 23-28, Paper OMAE2002-28604, 2002.

Jiménez, J. A., Sánchez-Arcilla, A., and Stive, M. J. F.: Discussion on prediction of storm/normal beach profiles, J. Waterw. Port. C-ASCE, 19(4), 466-468, 1993.
Jiménez, J. A., Ciavola, P., Balouin, Y., Armaroli, C., Bosom, E., and Gervais, M.: Geomorphic coastal vulnerability to storms in microtidal fetch-limited environments: Application to NW Mediterranean \& N Adriatic Seas, J. Coast. Res., SI 56, 16411645, 2009.

Jiménez, J. A., Sancho, A., Bosom, E., Valdemoro, H. I., Guillén, J., and Galofré, J.: Validation of vulnerability assessment to storms at the Catalan coast (NW Mediterranean) during the last 50 years, Proc. 32nd Coast. Eng. Conf., ASCE, Shanghai, China, June 30 July 5, in press, 2010.

McFadden, L., Nicholls, R. J., and Penning-Rowsell, E.: Managing Coastal vulnerability, Elsevier, 262 pp., 2007.

Mendoza, E. T. and Jiménez, J. A.: Factors controlling vulnerability to storm impacts along the Catalonian coast, Proc. 29th Int. Conf. on Coastal Engineering, ASCE, Lisbon, Portugal, September 1924, 3087-3099, 2004.

Mendoza, E. T. and Jiménez, J. A.: Storm-Induced Beach Erosion Potential on the Catalonian Coast, J. Coast. Res., SI 48, 81-88, 2006.

Mendoza, E. T. and Jiménez, J. A.: Regional geomorphic vulnerability analysis to storms for Catalan beaches, P. I. Civil Eng-Mar. En., 162, 3, 127-135, 2009.

Morton, R. A. and Sallenger, A. H.: Morphological impacts of extreme storms on sandy beaches and barriers, J. Coast. Res., 19, 560-573, 2003.

PAP/RAC: ICZM Protocol in the Mediterranean, Split, 2007.

Stockdon, H. F., Holman, R. A., Howd, P. A., and Sallenger, A. H.: Empirical parameterization of setup, swash, and runup, Coast. Eng., 53, 573-588, 2006. 